EGU2020-13644

https://doi.org/10.5194/egusphere-egu2020-13644

EGU General Assembly 2020

(c) Author(s) 2021. This work is distributed under

the Creative Commons Attribution 4.0 License.

\title{
The role of $\mathrm{SOM}_{\text {and }} \mathrm{CaCO}_{3}$ on soil aggregate development in reclaimed soils
}

\author{
Evelin Pihlap ${ }^{1,2}$, Markus Steffens $^{3}$, and Ingrid Kögel-Knabner ${ }^{1,4}$ \\ ${ }^{1}$ Chair of Soil Science, Research Department Ecology and Ecosystem Management, Technical University of Munich, Freising, \\ Germany (evelin.pihlap@wzw.tum.de) \\ ${ }^{2}$ Department of Geography, Institute of Ecology and Earth Sciences, University of Tartu, Tartu, Estonia \\ ${ }^{3}$ Department of Soil Sciences, Research Institute of Organic Agriculture (FiBL), Frick, Switzerland \\ ${ }^{4}$ Institute for Advanced Study, Technical University of Munich, Garching, Germany
}

Soil organic matter (SOM) and extracellular polymeric substances (EPS) from biological processes are considered to be major contributors in aggregate formation. But there is limited knowledge on soil structural formation after reclamation - the step when SOM content is low and soil properties are mostly controlled by the parent material. In our study we used a chronosequence approach in the reclaimed open-cast mining area near Cologne, Germany to elucidate the development of soil structure and soil organic matter during initial soil formation in a loess material. We selected six plots with different ages of agricultural management after reclamation $(0,1,3,6,12$, and 24 years after first seeding). In each reclaimed field 12 spatially independent locations were sampled with stainless steel cylinders $\left(100 \mathrm{~cm}^{3}\right)$ at two depths in the topsoil $(1-5 \mathrm{~cm}$ and $16-20 \mathrm{~cm})$. Samples were wet sieved into four aggregate size classes of $<63 \mu \mathrm{m}, 63-200 \mu \mathrm{m}, 200-630 \mu \mathrm{m}$ and $630-2000$ $\mu \mathrm{m}$. Each aggregate size class was characterized by organic carbon (OC), total nitrogen (TN) and $\mathrm{CaCO}_{3}$ concentration. The chemical composition of the SOM of selected samples was characterized using solid-state 13C NMR spectroscopy.

Wet sieving into aggregate size classes showed different trends along the chronosequence. Contradicting relation between $\mathrm{CaCO}_{3}$ and $\mathrm{OC}$ contribution to aggregate size classes display two different mechanisms on soil aggregate formation in young loess derived soils. $\mathrm{CaCO}_{3}$ influenced aggregation predominantly in finer aggregate size classes, where the highest concentration and contribution was measured. SOM, on the other hand, played an important role on formation of large macro-aggregates after organic manure application in year 4. Furthermore, the loss of total OC after year 12 was connected with the loss of OC contributing to the largest aggregate size class. Our findings reveal that $\mathrm{SOM}$ and $\mathrm{CaCO}_{3}$ role on stabilizing aggregates is not equally distributed and is aggregate size class dependent. 